\title{
A Modeling Technique for Rural Economies
}

\author{
Robert N. Barone*
}

Over the past 20 years there has been growing concern over the impacts of industrial and economic development on the quality of human life. The term "Environmental Impact Statement" (EIS) has become common parlance among planners and developers. Each major economic project must be accompanied by an EIS. As a result, a service industry, specializing in such studies, has grown up.

The alarming disintegration of the physical environment in and around large metropolitan areas has caused large industrial and utility companies to look toward rural areas to increase their capital stock. Such development has caused concern among many in the rural areas, some of whom have moved there to escape the environment of the city. Most concerns emanating from the rural areas involve the impacts such projects may have on their socioeconomic structures and rural way of life.

From this discussion, it appears that the EIS is an important document in any rural area's consideration of proposed industrial projects. Proper methodology in the preparation of such documents is a paramount consideration. The objective of this paper is to propose an appropriate methodology for the socioeconomic aspects of the EIS.

\section{ALTERNATIVE APPROACHES}

Glickman [5] discusses several alternative modeling techniques which would be appropriate for the socioeconomic analysis of regional economies. They are:

a) Economic-base models

b) Input-Output models

c) Econometric models

The basic tenet of economic base models is that the viability of a region is dependent on its ability to "export" goods and services to other regions. Those sectors which "export" are termed "basic" sectors. The non-export sectors (also called "service" or "non-basic") exist to service the resultant population. The usual formulation of the economic base model begins with a dichotomiza-

\footnotetext{
* The author is Associate Professor of Managerial Sciences in the College of Business Administration at the University of Nevada/Reno.
} 
tion of employment into basic and non-basic, and the assumption that the relationship between the sectors is stable.

A second and more sophisticated approach to regional analysis is known as input-output analysis. This approach is more realistic since it portrays the economy as multi-sectored. At great pains and expense, data is gathered which forms a matrix of interindustry relationships. This powerful tool can take into account complex interindustry relationships and the multiple impacts on a region's economy of a particular exogeneous event.

A third approach, and one gaining in popularity, is called econometric modeling. Most of these models begin with a theoretical economic structure and use regression analysis or some other form of statistical technique to tie economic variables together and to uncover relationships with exogeneous (national) variables.

\section{CRITICISMS OF EACH APPROACH}

Each approach described above suffers from its own peculiar maladies. In this section some of these problems are discussed.

\section{Economic Base Models}

As noted by Glickman, the use of employment numbers alone may bias the outcome of economic base models depending on whether or not employment changes occur in a high or low wage industry. That is, a job in a high wage industry may generate more employment in the service sectors than one in a low wage industry [5, p.21]. Also a problem may arise as to the basic/non-basic classification of an industry which serves both local needs and exports. Another noted problem is the instability of the basic/non-basic employment ratio. Productivity changes at different rates in different industries may cause the ratio to shift [8, p.236]. Isard [10] comments that the ratio may never be in equilibrium and may be constantly adjusting with various lags to continuous economic forces.

\section{Input-Output Analysis}

The basic criticism of this methodology is its expense [5, pp.34-37] [9, pp.164-165]. The interindustry data matrix requires extensive data gathering efforts including detailed firm and household surveys. The data rapidly become obsolete as the area grows and change occurs, thus requiring another round of in-depth and expensive surveys.

\section{Econometric Models}

Glickman observes that most smaller regions collect little economic data on themselves. Thus, statistical techniques have very few degrees of freedom which limits the number of independent variables. This results in misspecification problems. Most of the models that have been estimated are 
annual in nature and are tied to national variables. In fact, the data that is available often influences the direction of research [5, pp.61-64].

\section{THE RURAL AREA METHODOLOGY}

Because of the expense involved in input-output analysis and the relatively small and simple nature of most rural areas, this method appears inappropriate. The author does not believe that, in most cases, any better results could be obtained using this technique than the one chosen. The econometric modeling approach is rejected because of too few degrees of freedom, but mostly because of a lack of data on basic modeling necessities such as consumption, investment, interest rates, exports, and imports. Thus, the economic base technique appears to be the most appropriate. Still, the criticisms raised in the last section need to be addressed.

The use of a single basic/non-basic employment ratio may not be as serious a problem as it first appears. Many rural economies are based on a single industry which is most likely to be the focus of employment changes. Employment and income data are usually collected for establishment based employers by some higher level of government and are available. A statistical measure of the stability of the basic/non-basic and income/employment ratios should tell the researcher if problems exist in this area. The case study in this paper addresses this problem specifically.

Various schemes have been proposed to answer the criticism that some sectors may be part basic and part non-basic. These include location quotients [13] [15], minimum and maximum requirements techniques [14] [12] [6], and finally, firm by firm interviews. Glickman describes the last as quite expensive but the most accurate [5, p.25]. For most rural economies, however, this last method is the only method available because of the lack of data which the other methods require. And, in many rural economies, the method is really quite inexpensive due to the limited area of coverage. This is even more true when there is cooperation by the local chamber of commerce or equivalent service organization (which is usually pushing for the project under consideration).

\section{THE DATA PROBLEM}

The most formidable problem, even with the economic base method, is data. Most rural economies have little information on themselves; what is available is generally too aggregated, beset by estimation problems, or too old. The remainder of this paper describes techniques used to address this problem.

The raison d'etre of an EIS revolves around the "impacts" a particular project will have on the area under consideration. In order to measure the "impact", it is necessary to first forecast what would happen in the economy without the project (called the "baseline forecast"), then forecast the region with 
the project. The differences are defined as the "impacts". Forecasting calls for some modeling technique which uses parameters formed from historical data. And herein lies the problem. In order to do any socioeconomic analysis, data on employment and population are required.

What are generally available for the rural area are the following historical series:

a) Decennial census data;

b) Annual population estimates made by the U.S. Census Bureau;

c) Establishment based employment data (number of jobs);

d) Public and private school enrollments.

The decennial census data is certainly an accurate picture of the structure and composition of the area's population at the time it is taken. But in the ensuing ten years, much change may occur, especially in a rural environment in which the economic base begins as a small entity.

The annual Census Bureau population estimates are too aggregated; the techniques used are also suspect. For example, in the state of Nevada, the Census Bureau used the following regression estimate for both urban and rural counties to estimate the annual population in the 1970s:

$$
\mathrm{P}=.0094-.0284 \mathrm{~B}-.0301 \mathrm{D}+.3458 \mathrm{~S}+.7118 \mathrm{~V}
$$

where:

$\mathrm{P}=$ county population;

$\mathrm{B}=$ births in the county;

$\mathrm{D}=$ deaths in the county;

$\mathrm{S}=$ county school enrollments;

$\mathrm{V}=$ vehicles registered in the county.

First, it would be surprising if the regression performed well for both urban and rural counties; second, note that the sign on the coefficient for births is inappropriate.

Establishment based employment data are usually collected at the state level for the administration of social and welfare programs. Unfortunately, in most states, the coverage is not exhaustive. The individual researcher must determine the quality of this data and decide whether or not it should be supplemented or adjusted.

The school enrollment data provided by the local board of education is normally the most reliable data the researcher will obtain.

\section{THE MODELING TECHNIQUE}

\section{Cohort-Survival-Migration Model}

The socioeconomic analysis requires population by age and sex in order to determine labor force, unemployment and migration. Therefore, a cohort-survival-migration model is used to determine annual population structures in the historical period. Using demographic data from the most recent decennial 
FIGURE 1

The Demographic-Employment-Simulation Model

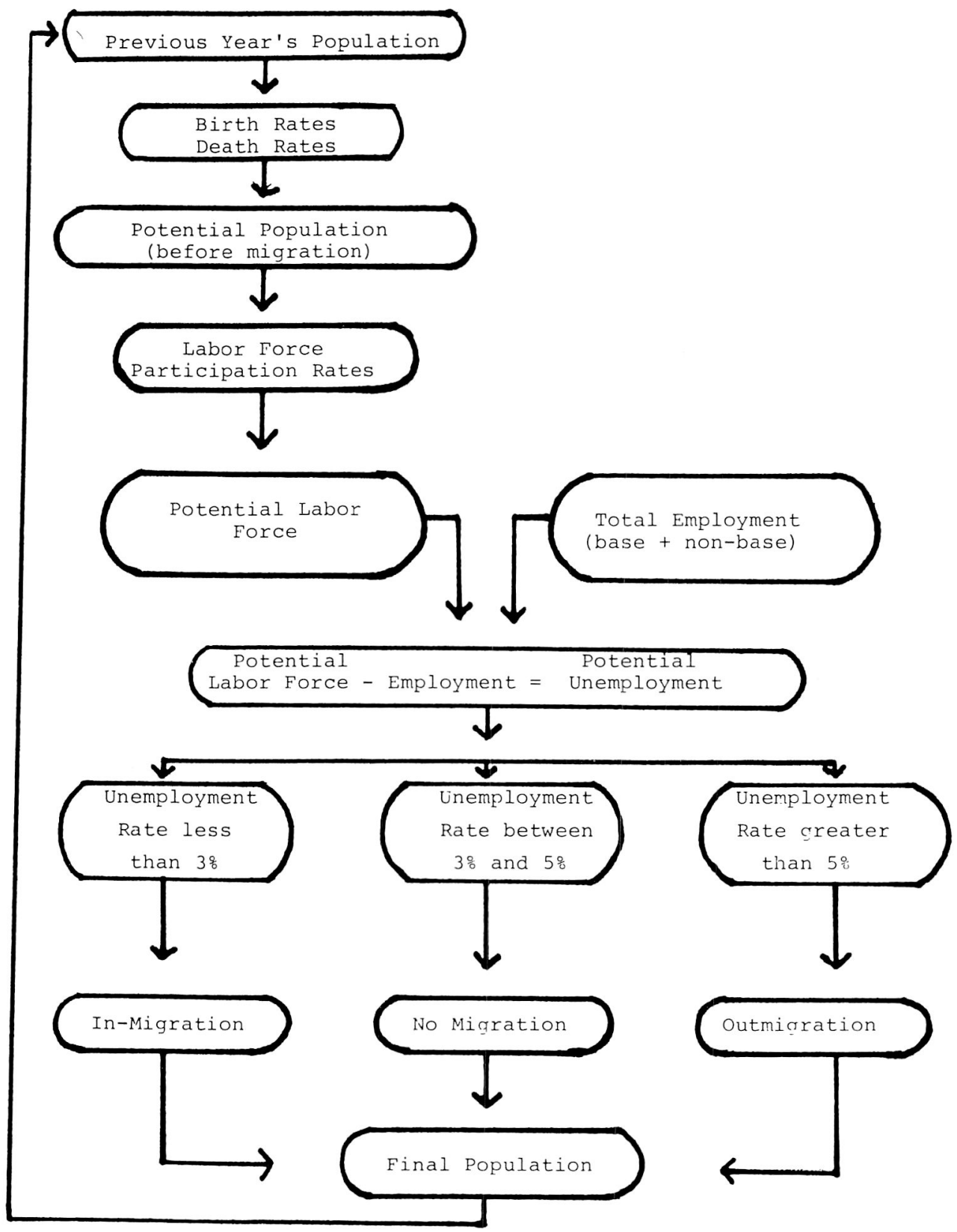


census (1970 in the case analysis), vectors of survival rates (specific to each state) can be applied to the existing population and fertility rates to the females. The resulting population (one year older) can be compared to the Census Bureau's annual population estimate for the area. If the population in the model is different from that estimated by the Census Bureau, age and sex specific propensities to migrate (again specific to each state) can be applied. The end result is the Census Bureau's population estimate with an age and sex structure attached. This new population structure serves as the starting point for the next year. And these population structures can be tested against the school enrollment data for accuracy.

\section{Demographic-Employment-Simulation Model}

The cohort-survival-migration model provides population structures over the historical past; the in- and out- migrations were determined by a comparison of model results to Census Bureau annual population estimates. But such population estimates do not exist for the forecast period. Thus, a model which is independent of Census Bureau population estimates is a necessity. Such a model is shown in Figure 1.

The model's approach uses both demographic and employment data. In order to establish parameters for the forecast period, a simulation is first performed.

Following Figure 1, to the decennial census population structures, survival and fertility rates are applied. The result is termed "potential population", i.e., a picture of the demographics in the absence of migration forces. Migration is a phenomenon caused by employment opportunities. If there are boom conditions in the area, in-migrants are attracted to the jobs. Out-migration occurs if job opportunities do not exist and unemployment is high.

To the potential population estimate, a matrix of labor force participation rates is applied (age and sex specific) to determine the "potential" labor force. Given the historical employment figures (which should be adjusted from a number of jobs to a number of people concept to account for double job holders, etc.), and the "potential" labor force, a "potential" unemployment rate can be formed. Again, conceptually, this is the unemployment rate which would occur in the absence of migration.

The question of how rapidly migration occurs is a difficult one. Without an actual count, it appears impossible to directly estimate. So, an indirect estimation procedure must be used. An historical period of population and employment stability is chosen and unemployment rates are examined. From this examination, an equilibrium range for the unemployment rate is chosen. If the "potential" unemployment rate is above the equilibrium range, out-migration occurs; if below the range, in-migration. Assume a range of $3 \%$ to $5 \%$ is chosen. Then the mean, $4 \%$, can be thought of as the "natural unemployment rate" as Knut Wicksell first suggested. Any "potential" unemployment rate above $5 \%$ stimulates out-migration; any below $3 \%$ in-migration. The number 
by which the "potential" unemployed is above (or below) the number determined by the natural unemployment rate is called the "excess" unemployed (and may be positive or negative).

Equilibrium does not occur immediately. The estimates of how quickly the migration occurs is done through the simulation process. Several mathematical algorithms should be chosen and tested. The complexity of the algorithm is at the researcher's discretion. The algorithm calculates a percentage of the "excess" unemployed that migrate, with more rapid migration occurring as the gap between the natural and potential rates widen. The algorithm which simulates the best results in the historical period is chosen for the model.

When migration occurs to or from the labor force, the migrants move with their families. In the model, the total number migrating is a variable which depends on population structure. In this case:

$$
\mathrm{M}=(\mathrm{P} / \mathrm{L})+\mathrm{U}
$$

where:

$\mathrm{M}=$ Total migration;

$\mathrm{P}=$ Potential population;

$\mathrm{L}=$ Potential labor force;

$\mathrm{U}=$ Number migrating from the labor force.

The total number migrating are distributed throughout the population by applying a matrix of propensities to migrate by age and sex (state specific). Thus, a final population and structure is formed which becomes the beginning structure for the next period's simulation.

\section{The Forecasting Model}

Now that all of the parameters are set, baseline forecasts can be made. The exogeneous data that is required is a starting population structure (which can be taken from either the cohort-survival-migration model or the simulation model) and employment forecasts.

Note that it is the number of jobs, not population, that must be exogeneously forecast. This is consistent with the earlier statement that migration is a phenomenon caused by employment opportunities. Too often, the socioeconomic aspect of the EIS is based upon a faulty logic in which forecasts of population, not employment, drive the model.

The impacts of a particular project are handled in the model somewhat differently. Figure 2 is similar to Figure 1 except:

a) The baseline employment projection is assumed;

b) The project itself is shown enclosed in dashed lines.

\section{BASELINE EMPLOYMENT}

The baseline employment forecasts can be done by one of two techniques:

a) Survey the employers in the "basic" industries. Such a survey which examines future growth prospects together with historical trends can lead to ex- 
FIGURE 2

The Forecast Model

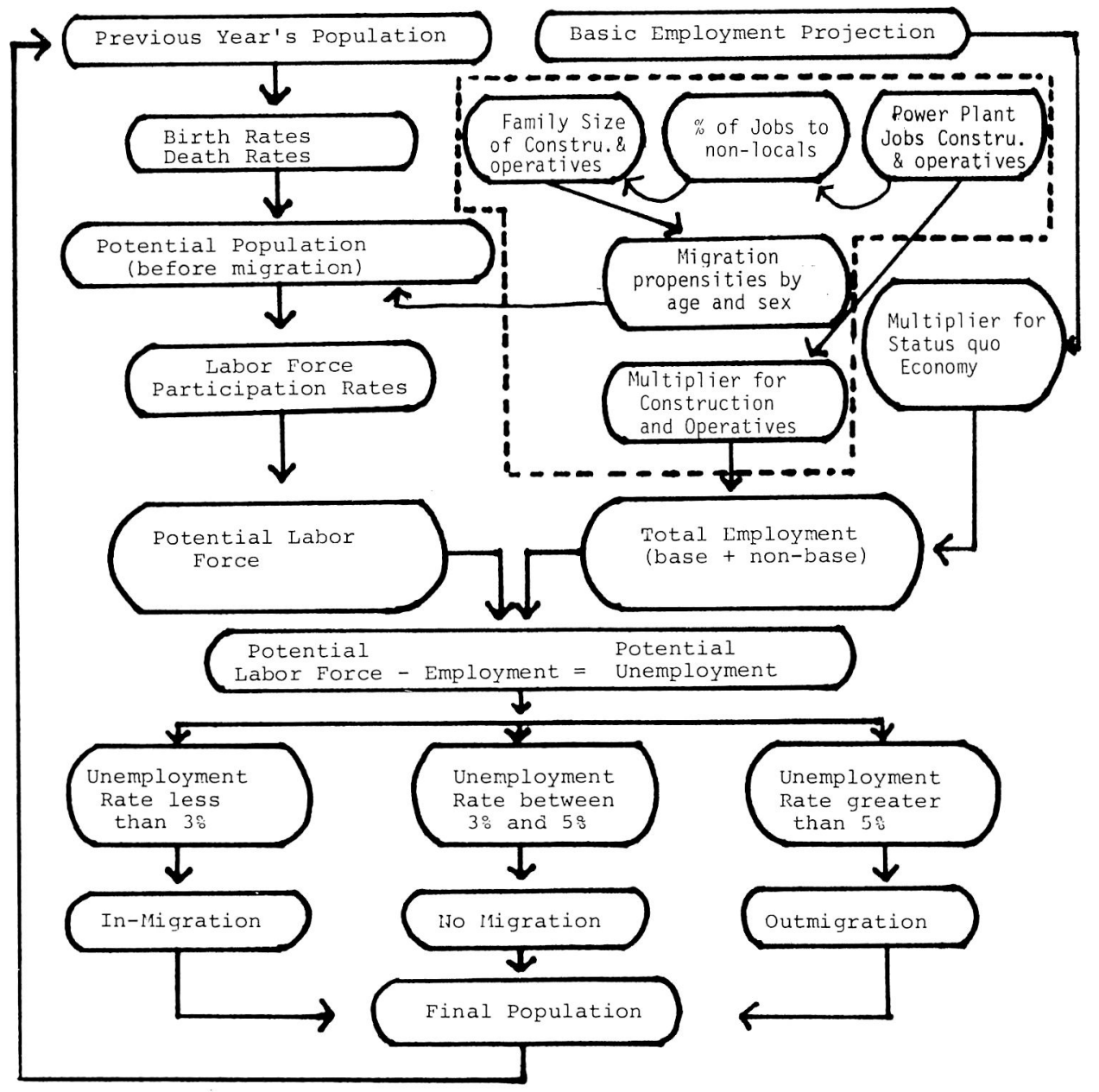


cellent employment forecasts. The application of the basic/non-basic historical relationship would determine employment in the "non-basic" industries.

b) For those researchers who believe the problems of "basic/non-basic" industry identification and shifting "basic/non-basic" employment ratios are major problems, some other means of a baseline employment forecast must be designed. Again, in a rural area, a survey of all business may not be out of the question. Or, perhaps, trend analysis by employment sector could be appropriate.

\section{THE PROJECT}

Engineering estimates provide a schedule of construction and operations workers for the project. It is assumed that all the jobs are filled as they are needed. In most rural areas there is a lack of population and skills and the vast majority of direct project employment is filled by non-locals. Construction and operations workers come from different socioeconomic strata. Construction workers are mobile and have small families while operations people become permanent residents of the community and tend to have larger families. The specific parameters can be determined from the experiences of other similar projects.

Having determined the number of migrants which would be attracted by the project employment requirements, vectors for migration propensities by age and sex are applied. Again, because of the socioeconomic differences, different migration propensities should be developed for construction workers and for other migrants [2]. The structure of the migrating population is thus determined and these are added to the potential population developed from the prior year's population as explained earlier. In this way, the construction and operations workers and their spouses are included in the labor force when the labor force participation rates are applied.

The construction and operations jobs themselves generate jobs in the nonbasic sector. Construction workers and operations people place different demands upon the economy. The ratios of the construction/non-basic and operations/non-basic must be separately estimated.

The remaining model mechanics are the same as those described for the simulation model.

\section{CASE ANALYSIS: WHITE PINE COUNTY, NEVADA}

Since the proof of the pudding is in the eating, this section illustrates the use of the model and shows results obtained.

Los Angeles Water and Power Company has proposed the building of a $1,350,000$ kilowatt coal fired electric generating plant in this rural county in eastern Nevada. The county consists of 8904 square miles. Most of the land is publicly owned, administered by the Bureau of Land Management and the Forest Service. 
TABLE 1

Mining, Population, and Unemployment in White Pine County, 1970-78

\begin{tabular}{|c|c|c|c|}
\hline Year & $\begin{array}{c}\text { Mining and Manufacturing } \\
\text { as a \% of } \\
\text { Basic Employment }\end{array}$ & Population* & $\begin{array}{l}\text { Unemploymen } \\
\text { rate }^{* * *}\end{array}$ \\
\hline 1970 & $75.6 \%$ & 10,150 & $3.9 \%$ \\
\hline 1971 & $74.3 \%$ & 10,000 & $5.3 \%$ \\
\hline 1972 & $73.8 \%$ & 10,300 & $5.9 \%$ \\
\hline 1973 & $75.6 \%$ & 10,001 & $5.2 \%$ \\
\hline 1974 & $74.5 \%$ & 10,000 & $4.7 \%$ \\
\hline 1975 & $71.4 \%$ & 10,100 & $10.0 \%$ \\
\hline 1976 & $57.1 \%$ & 9,796 & $23.3 \%$ \\
\hline 1977 & $60.4 \%$ & 8,481 & $7.8 \%$ \\
\hline 1978 & $44.4 \%$ & $8,335^{* *}$ & $13.8 \%$ \\
\hline
\end{tabular}

* Census estimates

** Estimated by the study

*** Estimated by ESD

The population, estimated to be 8,300 in 1978 , is concentrated in the towns of Ely, East Ely, McGill and Ruth. These towns are all in close proximity and thus were treated as a single socioeconomic unit. The nearest major metropolitan areas are Salt Lake City to the east (approximately 230 miles), Reno to the west (approximately 317 miles) and Las Vegas to the southwest (approximately 284 miles). The nearest interstate highway is I-80, approximately 72 miles to the north.

The basic history of White Pine County is closely tied to mining. In the 19 th century, the gold and silver rushes attracted many to eastern Nevada; but in the 20th century, copper mining has been the economic mainstay, specifically, Kennecott Copper Company. Tourism, basically due to legal gaming in Nevada, runs a poor second to mining in the overall economic picture. Besides mining and tourism, White Pine County contains very little "basic" employment.

Beginning in 1975, Kennecott began phasing out its copper mine located in Ruth. In February, 1976, the mine was closed for 10 months. Then, in 1977, it was partially reopened, only to be closed again in 1978, this time permanently. The mine closure appears to be directly related to the volatility of the price of copper which was fluctuating between $\$ .50$ and $\$ .95$ per pound in 1978 and 1979, and to the low quality of the ore remaining in the Ruth mine after years of extraction.

Table 1 shows the dependence of this rural economy on the copper mine. Shown in the table are mining and manufacturing as a percent of total basic employment, population estimates, and the unemployment rate. The population estimates are the "official" census estimates and the unemployment rate is 
TABLE 2:

Employment Sectors and the Percent of Basic Employment in White Pine County, 1978

\begin{tabular}{lc}
\hline \multicolumn{1}{c}{ Sector } & \% Basic \\
\hline Mining \& Manufacturing & 99 \\
Construction & 0 \\
Transportation & 75 \\
Finance, Insurance \& Real Estate & 0 \\
Service Stations & 57 \\
Eating \& Drinking Places & 46 \\
Hotels \& Gaming & 76 \\
Other Services & 0 \\
Government & 9 \\
Farm & 100 \\
Nonfarm Proprietors & 13 \\
\hline
\end{tabular}

that estimated by the Nevada Employment Security Department (ESD). Note the influence of mining on population and the unemployment rate, especially in the $1976-78$ period.

\section{THE DATA}

The historical data available consisted of the following series:

a) 1970 census data;

b) 1971-77 Census Bureau population estimates;

c) 1970-78 covered employment estimates by industry and unemployment rates from ESD;

d) 1970-78 Bureau of Economic Analysis estimates of the number of farm and non-farm proprietors;

e) 1970-78 public and private school enrollments.

The covered employment data from ESD included nine industries; to those nine the data provided by the Bureau of Economic Analysis were added. In order to determine the percentage of each sector that provided "basic" employment, extensive interviews in the area were conducted in the spring of 1979. Table 2 shows the results obtained from the research gathering process. Specifically, it shows the sectors and the percentage of "basic" employment in those sectors in 1978. From examination of the table, it can be seen that most of the mining and manufacturing, and most of the farm products were exported from the region, while the construction, finance, and other services were consumed locally. About half of the service station services and products and half of the restaurant meals were consumed by locals; therefore, the other half were consumed by outsiders. By applying the ratios from the table to ESD and BEA employment data, the employment "base" was estimated. 
TABLE 3

The Relationships of Basic and Non-Basic Employment in White Pine County: Actual 1970-78; Estimated 1979-95

\begin{tabular}{|c|c|c|c|c|}
\hline Year & Basic & Non-Basic & Total & Total/Basic \\
\hline 1970 & 2128 & 1979 & 4107 & 1.93 \\
\hline 1971 & 1961 & 2001 & 3962 & 2.02 \\
\hline 1972 & 1963 & 2073 & 4036 & 2.06 \\
\hline 1973 & 1995 & 2001 & 3996 & 2.00 \\
\hline 1974 & 2151 & 1979 & 4130 & 1.92 \\
\hline 1975 & 1840 & 1950 & 3790 & 2.06 \\
\hline 1976 & 1274 & 1890 & 3164 & 2.48 \\
\hline 1977 & 1595 & 1934 & 3519 & 2.21 \\
\hline 1978 & 1223 & 1910 & 3133 & 2.56 \\
\hline 1979 & 994 & 1552 & 2546 & 2.56 \\
\hline 1980 & 1143 & 1372 & 2515 & 2.20 \\
\hline 1981 & 1162 & 1282 & 2444 & 2.10 \\
\hline 1982 & 1181 & 1238 & 2419 & 2.05 \\
\hline 1983 & 1200 & 1193 & 2393 & 1.99 \\
\hline 1984 & 1214 & 1193 & 2407 & 1.98 \\
\hline 1985 & 1228 & 1193 & 2421 & 1.97 \\
\hline 1986 & 1242 & 1193 & 2435 & 1.96 \\
\hline 1987 & 1256 & 1193 & 2449 & 1.95 \\
\hline 1988 & 1225 & 1193 & 2418 & 1.97 \\
\hline 1989 & 1199 & 1193 & 2392 & 1.99 \\
\hline 1990 & 1173 & 1193 & 2366 & 2.02 \\
\hline 1991 & 1187 & 1193 & 2380 & 2.01 \\
\hline 1992 & 1201 & 1193 & 2394 & 1.99 \\
\hline 1993 & 1215 & 1193 & 2408 & 1.98 \\
\hline 1994 & 1229 & 1193 & 2422 & 1.97 \\
\hline 1995 & 1243 & 1193 & 2436 & 1.96 \\
\hline
\end{tabular}

The establishment of the employment base allowed an examination of the relationship of total/basic employment in the 1970-78 period. The top part of Table 3 shows that relationship. The lower portion of that table shows the aggregated sector employment forecasts. For the years 1970-75 a ratio of approximately 2.0 existed (the mean value for the 6 years is 1.9983). But in the 1976-78 period, it is apparent that basic employment fell much faster than non-basic employment. This was obviously due to the closure of the Ruth copper mine. The result was an apparent disequilibrium in the level of non-basic employment. There are several reasons for the length of time that this disequilibrium situation existed:

a) Social insurance:

Both unemployment benefits and Trade Readjustment Act payments kept income from falling as rapidly as employment. Thus, the service sector (non- 
TABLE 4

Actual and Estimated School Enrollments in White Pine County, 1970-78

\begin{tabular}{ccccc}
\hline Year & $\begin{array}{c}\text { School Enrollments } \\
\text { Grades } 1-8\end{array}$ & $\begin{array}{c}\text { Estimated } \\
6-13 \text { yrs. }\end{array}$ & $\begin{array}{c}\text { Estimate } \times \\
.979\end{array}$ & Variance \\
\hline 1970 & 1781 & 1819 & 1781 & 0 \\
1971 & 1755 & 1768 & 1731 & 24 \\
1972 & 1604 & 1748 & 1711 & -107 \\
1973 & 1605 & 1673 & 1638 & -33 \\
1974 & 1557 & 1598 & 1564 & -7 \\
1975 & 1523 & 1585 & 1552 & -29 \\
1976 & 1269 & 1539 & 1507 & -238 \\
1977 & 1346 & 1384 & 1355 & -10 \\
1978 & 1144 & 1281 & 1254 & -110 \\
\hline
\end{tabular}

basic) employment remained high as demand from the unemployed remained robust.

b) Uncertainty:

Through the 1976-78 period there was some uncertainty concerning the permanency of the mine closure. This was fueled by the re-opening of the mine in 1977.

c) Paternalism:

It was apparent from the interviews that employers in this rural area felt somewhat responsible for their employees' well being, especially long time employees. Thus, they were likely to keep these employees on as long as possible.

d) Discreet employment functions:

In a small economy, such as that under consideration, discontinuities in the employment functions may become important during recessions. A single service worker, say, a retail counter clerk, capable of handling 10 customers/hour, may still have to be retained if business falls to 5 customers/hour.

\section{APPLICATION OF THE METHODOLOGY}

\section{The Cohort-Survival-Migration model:}

The simulated population aged 6-13 was tested against school enrollments in grades 1 to 8 (including public school, special education, and private school enrollments). The 1970 census estimated 1819 in White Pine County were aged 6-13. Actual school enrollments were 1781, or 97.9\% of those aged 6-13. The discrepancy exists because the census is taken in April and the school enrollments in October. (The official population estimates are as of July 1.) Table 4 shows actual school enrollments and the model estimates of the $6-13$ age group range. 
TABLE 5

Simulation Results for White Pine County, 1971 - 1978

\begin{tabular}{|c|c|c|c|c|c|c|c|c|}
\hline \multirow{2}{*}{ Year } & \multicolumn{2}{|l|}{ Population } & \multicolumn{4}{|c|}{ School Enrollment' } & \multicolumn{2}{|c|}{$\begin{array}{c}\text { Unemployment } \\
\text { Rate }\end{array}$} \\
\hline & Census & Model Est. & Actual & Model Est. & ESD & Model Est. & ESD & Model Est. \\
\hline 1971 & 10,000 & 10,150 & 1755 & 1746 & 4214 & 4165 & 5.3 & 6.8 \\
\hline 1972 & 10,300 & 10,209 & 1604 & 1702 & 4200 & 4198 & 5.9 & 5.8 \\
\hline 1973 & 10,001 & 10,181 & 1605 & 1655 & 4052 & 4223 & 5.2 & 7.3 \\
\hline 1974 & 10,000 & 10,292 & 1557 & 1593 & 4260 & 4283 & 4.7 & 5.5 \\
\hline 1975 & 10,100 & 9,892 & 1523 & 1526 & 4225 & 4151 & 10.0 & 10.5 \\
\hline 1976 & $9,796^{2}$ & 8,513 & 1269 & 1366 & $4046^{2}$ & 3556 & 23.3 & 12.8 \\
\hline 1977 & 8,841 & 8,710 & 1346 & 1335 & 3856 & 3566 & 7.8 & 3.0 \\
\hline 1978 & N.A. & 8,336 & 1144 & 1249 & 3245 & 3442 & 13.8 & 10.8 \\
\hline
\end{tabular}

'Includes: special, ungraded and parochial

'This estimate is clearly incorrect given the loss of 254 student (grades 1-8) from 1975 to 1976.

It is apparent from school enrollment data in the table that the census population estimate of 9796 (Table 1) for 1976 is too high. The layoffs at Kennecott in February 1976 obviously caused a massive migration by the time school started in September. A population of 8512 for 1976 appears to be more consistent with school enrollments and the estimated population structure. Population estimates by the Census Bureau for 1972 also appear to be somewhat high.

\section{The Demographic Employment Simulation:}

The simulation model used the 1971-78 employment estimates shown in Table 3 and the 1970 decennial census population structures. From Table 1 it can be seen that during the 1970-74 period of population stability, the unemployment rate fluctuated between $3.9 \%$ and $5.9 \%$. Thus, the unemployment equilibrium range was chosen to be $4 \%$ to $6 \%$ and the "natural rate" of unemployment set at $5 \%$.

The speed with which migration in the labor force occurs was chosen through the simulation process. In this case, the following algorithm was chosen:

$$
\begin{aligned}
& X=0 \text { if } 4<U P<6 \\
& X=30+\operatorname{ABS}(2(\text { UP-UN }))
\end{aligned}
$$

where:

$X=$ percentage of "excess" labor force migrating;

$\mathrm{UP}=$ potential unemployment rate:

$\mathrm{UN}=$ natural unemployment rate:

$\mathrm{ABS}=$ absolute value.

Thus, if UP $=8 \%$ and UN $=5 \%$, then $36 \%$ of the "excess" unemployed will immediately migrate. "Excess" unemployment is defined as the difference between UP and UN. Table 5 shows the results of the simulation. 
TABLE 6

Baseline Forecasts and Impact of Power Plant on Population, Enrollment, and Employment in White Pine County 1979 - 1995

\begin{tabular}{rcrrrrrrr}
\hline & & & \multicolumn{3}{c}{ Population } & \multicolumn{3}{c}{ Unemployment } \\
Year & Population & Population & \multicolumn{2}{c}{$6-13$} & \multicolumn{2}{c}{ Employment } & \multicolumn{2}{c}{ Rate } \\
\hline 1979 & B & P & B & P & B & P & B & P \\
\hline 1980 & 6958 & 6958 & 1102 & 1102 & 2546 & 2546 & 13.2 & 13.2 \\
1981 & 6625 & 6792 & 1058 & 1058 & 2515 & 2515 & 9.7 & 9.7 \\
1982 & 6541 & 6625 & 1039 & 1039 & 2444 & 2444 & 9.8 & 9.8 \\
1983 & 6476 & 6541 & 1038 & 1038 & 2419 & 2419 & 8.8 & 8.8 \\
1984 & 6462 & 6476 & 1007 & 1007 & 2393 & 2393 & 8.6 & 8.6 \\
1985 & 6482 & 6655 & 983 & 1005 & 2407 & 2522 & 7.8 & 7.1 \\
1986 & 6519 & 7584 & 1006 & 1150 & 2421 & 3045 & 7.2 & 3.7 \\
1987 & 6575 & 9230 & 1025 & 1393 & 2435 & 3890 & 6.7 & 1.6 \\
1988 & 6582 & 11436 & 1048 & 1734 & 2449 & 4932 & 6.3 & .6 \\
1989 & 6555 & 11086 & 1069 & 1731 & 2418 & 4566 & 7.3 & 4.4 \\
1990 & 6511 & 9715 & 1081 & 1591 & 2392 & 3727 & 7.9 & 8.5 \\
1991 & 6516 & 8635 & 1084 & 1468 & 2366 & 3186 & 8.2 & 9.9 \\
1992 & 6541 & 8566 & 1090 & 1476 & 2380 & 3200 & 7.3 & 8.0 \\
1993 & 6571 & 8550 & 1102 & 1487 & 2394 & 3214 & 6.8 & 7.2 \\
1994 & 6599 & 8551 & 1110 & 1488 & 2408 & 3228 & 6.6 & 7.0 \\
1995 & 6617 & 8553 & 1123 & 1482 & 2422 & 3242 & 6.6 & 6.9 \\
\hline
\end{tabular}

$\mathrm{B}=$ Baseline

$\mathrm{P}=$ White Pine Power Project Overlay

The Forecasts:

Table 3 shows the employment assumptions made for the area. The employment figures in the basic industries were generated from direct interviews and trend analysis.

It appears that the service sector of the economy had excess capacity in the 1976-78 period. For purposes of the baseline forecasts of the non-basic sector the following assumptions were made:

a) Social insurance programs, once terminated, would cause the loss of service (non-basic) jobs;

b) As time passed, especially through the 1978 period, the population would become convinced that the mine closure was permanent.

It was assumed that these two forces would bring the total/basic employment ratio back to the equilibrium level of 2.0 within 3 years. The bottom portion of Table 3 shows the results of those assumptions.

The beginning population structure was taken as the 1977 result of the cohort-survival-migration simulation. Other model assumptions were:

a) The percentage of non-locals hired for the construction and operation of the plant would be $90 \%$; 
b) The construction worker family size was 2.28 people;

c) Operations personnel family size was 3.05 people [2];

d) Because construction workers place different demands upon the economy than do permanent residents, it was estimated that for each construction job only .36 non-basic jobs would result; for each operations job, 1 nonbasic job would be created. The social economy was assumed to perceive the temporary nature of the construction jobs and would not gear up as much as it did for the operations personnel whose jobs would be a permanent addition to the economy. The 1.36 multiplier was derived from a regression of total earnings to basic earnings. Since earnings are more sensitive to short run economic changes than employment, the 1.36 was chosen as a short-term multiplier to be applied to identifiable temporary changes.

Table 6 shows part of the impact of the proposed power plant on population, enrollments, and employment in the area.

\section{CONCLUSION}

This paper has attempted to present a methodology for assessing the impacts of a project on a rural socioeconomic environment. The results of the case study indicate that it is possible to develop consistent models even when there is a dearth of reliable data. The simulation results (Table 5) indicate that the population structures can be accurately simulated as shown by the school enrollment results, and that the "official" population estimates made by the Census Bureau may not always reflect reality.

\section{REFERENCES}

1. Boster, R. L. and W. E. Martin. "The Value of Primary vs. Secondary Data in Interindustry Analysis: A Study in the Economics of Economic Models", The Annals of Regional Science, 1972.

2. Construction Worker Profile Final Report, Old West Regional Commission, 1975.

3. Drake, R. L. "Evaluation of a Shortcut Method for Estimating Regional Final-Demand Multiplier", unpublished paper delivered at Regional Science Association, San Diego, 1976.

4. Gillies, James and William Grigsby. "Classification Errors in Base-Ratio Analysis", Journal of the American Institute of Planners, 1956.

5. Glickman, Norman J. Econometric Analysis of Regional Systems. New York, Academic Press, 1977.

6. Greytak, D. "A Statistical Analysis of Regional Export Estimating Techniques," Journal of Regional Science, 1969.
7. Hansen, W. L. and C. M. Tiebout. "An Intersectoral Flow Analysis of the California Economy", Review of Economics and Statistics, 1963.

8. Harris, Britton. "Comments on Pfout's Test of the Base Theory", Journal of the American Institute of Planners, 1958.

9. Heibrun, James. Urban Economics and Public Policy. New York, St. Martin's Press, 1974.

10. Isard, Walter. Methods of Regional Analysis: An Introduction to Regional Science. Cambridge, Mass., MIT Press, 1960.

11. Matilla, John M. and Wilbur R. Thompson. "The Measurement of the Economic Base of the Metropolitan Area", Land Economics, 1955.

12. Pratt, R. T. "An Appraisal of the Minimum Requirements Techniques", Economic Geography, 1968.

13. Thompson, Gerald E. "An Investigation of the Local Employment Multipliers", The Review of Economics and Statistics, 1959. 
14. Ullman, E. L. and M. F. Dacey. "The Minimum Requirements Approach to the Urban Economic Base", Papers of the Regional Science Association, 1960.
15. Weiss, Steven J. and Edwin C. Gooding. "Estimation of Differential Employment Multipliers in a Small Regional Economy", Land Economics, 1968. 